\title{
ANALISIS SALURAN PEMASARAN JAMUR TIRAM PUTIH (Studi Kasus di Desa Rajadesa Kecamatan Rajadesa Kabupaten Ciamis)
}

\author{
AHMAD FAUZAN ${ }^{1 *}$, DINI ROCHDIANI ${ }^{2}$, SUDRAJAT ${ }^{1}$ \\ ${ }^{1}$ Fakultas Pertanian Universitas Galuh \\ ${ }^{2}$ Fakultas Pertanian Universitas Padjajaran \\ *E-mail: fauzanahmad3391@gmail.com
}

\begin{abstract}
ABSTRAK
Jenis jamur ini banyak diminati karena cita rasanya yang lezat dan bisa dibuat menjadi berbagai macam olahan masakan. Prospek jamur yang bagus dan minat masyarakat yang semakin meningkat dalam mengkonsumsi jamur, membuat banyaknya pembudidaya jamur di Indonesia. Sehingga penelitian ini bertujuan untuk mengetahui: (1) Saluran pemasaran jamur tiram putih dari petani ke konsumen di Desa Rajadesa Kecamatan Rajadesa Kabupaten Ciamis. (2) Besarnya marjin, biaya dan keuntungan dari masing-masing lembaga pemasaran jamur tiram putih di Desa Rajadesa Kecamatan Rajadesa Kabupaten Ciamis. (3) Besarnya bagian harga yang diterima petani (share) dari harga yang dibayarkan konsumen. Penelitian ini dilaksanakan pada petani jamur tiram putih di Desa Rajadesa dengan menggunakan studi kasus. Sampel yang di ambil adalah seorang petani jamur tiram putih dengan menggunakan teknik Purposive Sampling ( sampel yang sengaja dipilih atau tidak acak). Sedangkan untuk sampel lembaga pemasaran diambil dengan cara Snowball Sampling. Hasil penelitian menunjukkan bahwa : (1). Terdapat satu saluran pemasaran jamur tiram putih dari petani sampai ketangan konsumen akhir yaitu :Petani $\rightarrow$ Pedagang pengecer $\rightarrow$ Konsumen akhir, (2). Besarnya total marjin pemasaran adalah Rp. 4.000,00 per kilogram dengan total biaya pemasaran Rp. $1.366,70$ per kilogram dan total keuntungan pemasaran Rp. 2.633,30 per kilogram. (3). Besarnya bagian harga yang diterima petani (farmer's share) adalah sebesar 71,5 persen.
\end{abstract}

Kata kunci : Jamur Tiram Putih, Saluran Pemasaran

\begin{abstract}
This type of masroom is in great demand because of its delicious taste and can be made into a variety of processed dishes. Good mushroom prospect and increasing public interest in consuming mushrooms, making many mushroom cultivators in Indonesia. This study aims to determine: (1) Channels marketing white oyster mushrooms from farmers to consumers in Rajadesa Village, Rajadesa District, Ciamis Regency. (2) The amount of margin, costs and benefits of each white oyster mushroom marketing agency in Rajadesa Village, Rajadesa District, Ciamis Regency. (3) The amount of the price received by the farmer (share) from the price paid by the consumer.This research was conducted on the only white oyster mushroom farmer in Rajadesa Village using a case study. The samples taken were white oyster mushroom farmer using Purposive Sampling techniques (samples that were deliberately chosen or not random). Whereas for marketing agency samples taken by means of Snowball Sampling the results of this study indicate that: (1). There is one marketing channel for white oyster mushrooms to the end consumer Namely: Farmers $\rightarrow$ Retailers $\rightarrow$ Consumers,(2). The amount of marketing margin for white oyster mushrooms is Rp. 4,000.00 per kilogram with a total marketing cost of Rp. 1.866 .70 per kilogram so that the total marketing profit is Rp. 2.633 .30 per kilogram, (3) The share of the price received by farmers (farmer's share) is 71.5 percent.
\end{abstract}

Keywords : white oyster mushroom,marketing channels.

\section{PENDAHULUAN}

Jamur tiram putih (Pleurotus ostreatus) merupakan jenis jamur pangan dari kelompok Basidiomycota. Jamur ini dapat ditemui di alam bebas sepanjang tahun. Jamur tiram merupakan salah satu jenis jamur kayu yang tumbuh di permukaan batang pohon yang sudah lapuk 
atau pada batang pohon yang sudah ditebang. Nama jamur tiram diambil dari bentuk tudungnya yang melengkung, lonjong, dan membulat menyerupai kerang atau cangkang tiram dengan bagian tepi yang bergelombang (Alex, 2011).

Kecamatan Rajadesa merupakan salah satu wilayah di Kabupaten Ciamis yang menghasilkan produk olahan hasil hutan bukan kayu, salah satunya jamur tiram. Banyaknya industri penggergajian kayu menjadi faktor ketersediaanya bahan baku yang melimpah untuk petani jamur tiram. Desa yang mengusahakan Jamur Tiram meliputi Desa Rajadesa, Desa Sirnabaya, Desa Tanjungjaya, dan Desa Tigaherang.

Pinem (2018) dalam penelitiannya yang berjudul Analisis Pemasaran Jamur Tiram Putih, menyatakan bahwa Saluran pemasaran jamur tiram putih yang terjadi ada tiga yaitu saluran pertama petani langsung ke konsumen akhir dengan persentase penjualan $7,87 \%$ dengan harga jual Rp 32.000,00/kg. Saluran kedua petani menjual ke pedagang pengecer dan pedagan pengecer menjualnya ke konsumen akhir dengan persentase penjualan $77,95 \%$ harga jual petani ke pedagang pengecer yaitu Rp.27.632,00/kg dan pedagang pengecer ke konsumen terakhir yaitu Rp. 40.000,00/kg. Saluran ketiga yaitu petani menjual ke pengumpul, kemudian pedagang pengumpul menjual ke pedagang pengecer dan pedagang pengecer menjual ke konsumen akhir dengan persentase $14,18 \%$ harga petani menjual ke pedagang pengumpul yaitu $\mathrm{Rp}$ $29.000,00 / \mathrm{kg}$ harga jual pedagang pengumpul ke pedagang pengecer yaitu $R p$ $36.000,00 / \mathrm{kg}$ dan harga jual pedagang pengecer ke konsumen akhir yaitu $\mathrm{Rp}$ $42.000,00 / \mathrm{kg}$.

Total biaya pemasaran yang dikeluarkan pada saluran pemasaran I, II, dan III yaitu sebesar Rp 533,00/kg, Rp $2.929,00 / \mathrm{kg}$, dan $\mathrm{Rp} 3.291,00 / \mathrm{kg}$. Total marjin pemasaran pada saluran pemasaran I,II dan III yaitu Rp 0,00/kg, Rp $12.368,00 / \mathrm{kg}$, dan Rp 13.000,00/g. Keuntungan pemasaran pada saluran I, II dan III yaitu Rp 31.467,00/kg, Rp 10.794,00/kg dan Rp 9.709.00/kg. Efisiensi pemasaran saluran pemasaran I, II dan III yaitu $16,7 \%, 73,2 \%$, dan 78,4\%. Dan Bagian yang diterima petani pada saluran pemasaran I,II dan III yaitu 100,00\%, $69,08 \%$, dan $69,05 \%$.

\section{METODE PENELITIAN}

\section{Lokasi dan Waktu Penelitian}

Penelitian ini dilaksanakan menggunakan metode studi kasus dengan mengambil kasus di Desa Rajadesa 
Kecamatan Rajadesa Kabupaten Ciamis. Menurut Daniel (2007), metode studi kasus lebih mirip dengan metode survei. Bedanya dalam studi kasus, populasi yang diteliti lebih terarah dan terfokus pada sifat tertentu yang tidak berlaku umum. Biasanya dibatasi oleh kasus, lokasi, tempat, serta waktu tertentu.

Penelitian ini dilaksanakan di Desa Rajadesa Kecamatan Rajadesa Kabupaten Ciamis. Adapun waktu penelitian dibagi dalam tahapan sebagai berikut:

1) Tahap persiapan yaitu survei pendahuluan, penulisan Usulan Penelitian dan Seminar Usulan Penelitian dilaksanakan pada bulan Januari sampai dengan Mei 2019.

2) Tahapan pengumpulan data dari lapangan, yaitu pengumpulan data primer dan data sekunder dilaksanakan pada bulan Mei sampai dengan Juni 2019.

3) Tahapan penulisan skripsi dilaksanakan pada bulan Juni 2019 sampai dengan selesai.

\section{Metode Pengambilan Sampel}

Sampel yang diambil dalam penelitian ini adalah petani jamur tiram putih yaitu ibu Tati yang menjadi satusatunya petani jamur tiram putih di Desa Rajadesa Kecamatan Rajadesa Kabupaten Ciamis. Teknik pengambilan sampel untuk petani jamur tiram putih menggunakan purposive sampling (sampel yang sengaja dipilih atau tidak acak). Menurut Nasehudin dan Gozali (2012), purposive sampling merupakan salah satu teknik sampling non random dimana peneliti menentukan ciri - ciri khusus yang sesuai dengan tujuan peneliti.

Jumlah sampel lembaga pemasaran dilakukan dengan menggunakan snow ball sampling. Sugiyono (2017) menyatakan bahwa snow ball sampling method adalah tehnik penentuan sampel yang mula-mula jumlahnya kecil, semakin lama semakin besar.

\section{HASIL DAN PEMBAHASAN}

saluran pemasaran adalah suatu jalur yang dilalui oleh suatu barang dari produsen atau petani ke perantara dan akhirnya sampai pada pemakai atau konsumen. Marjn pemasaran adalah selisih antara harga yang di terima produsen dengan yang dibayar oleh konsumen. Keuntungan pemasaran adalah selisih dari marjin pemasaran yang didapat oleh produsen atau lembaga pemasaran dengan total biaya di tingkat lembaga pemasaran.

Pemasaran merupakan kegiatan yang pruduktif karena mampu menciptakan kegunaan dari suatu barang, baik kegunaan karena tempat, kepemilikan 
dan kegunaan karena waktu, begitu pula dengan pemasaran jamur tiram putih yang ada di Desa Rajadesa.

Kegiatan pemasaran jamur tiram merupakan proses pengalihan jamur tiram dari petani ke konsumen akhir. Penyaluran jamur tiram dari petani sampai konsumen akhir melalui satu saluran pemasaran yaitu dari petani ke pedagang pengecer kemudian ke konsumen. Saluran pemasaran jamur tiram dari petani sampai konsumen akhir yaitu digambarkan sebagai berikut:

\section{Petani $\quad \rightarrow \quad$ Pedagang pengecer}

\section{Analisis Biaya, Marjin dan Keuntungan} Pemasaran antar Lembaga Pemasaran

Setiap lembaga pemasaran akan melakukan pemasaran yang dapat menciptakan kegunaan, baik guna bentuk, guna waktu, dan guna tempat sehingga dapat mempermudah konsumen untuk memperoleh jamur tiram putih. Dalam proses pengaliran produk dari petani sampai konsumen ternyata banyak perlakuan - perlakuan yang dilakukan oleh pedagang pengecer agar produk sampai ke konsumen sesuai dengan keinginan.

\begin{abstract}
Perlakuan - perlakuan yang dilakukan lembaga pemasaran dapat mempengaruhi besarnya biaya yang harus dikeluarkan oleh setiap lembaga pemasaran serta berpengaruh pula terhadap besarnya marjin dan keuntungan pemasaran.
\end{abstract}

Untuk melihat besarnya biaya yang dikeluarkan oleh pedagang pengecer dapat dilihat pada Tabel 1 .

\section{Tabel 1. Rata - rata Biaya Pemasaran Jamur Tiram Ditingkat Pedagang Pengecer}

\begin{tabular}{|c|c|c|c|}
\hline \multicolumn{2}{|c|}{ Konsumen akhir } & \multicolumn{2}{|c|}{ Besarnya Biaya } \\
\hline No & Jenis Biaya & $\mathrm{Rp} / \mathrm{Kg}$ & $\begin{array}{c}\text { Persentase } \\
(\%)\end{array}$ \\
\hline 1 & Transportasi & 700,00 & 51,23 \\
\hline 2 & Retribusi & 166,70 & 12,19 \\
\hline \multirow[t]{2}{*}{3} & Plastik & 500,00 & 36,58 \\
\hline & Jumlah & $1.366,70$ & 100,00 \\
\hline
\end{tabular}

Tabel 1 menunjukkan, bahwa jenis biaya yang paling besar adalah biaya transportasi yaitu 80,77 persen atau Rp. 700 per kilogram, sedangkan biaya retribusi yaitu 19,23 persen atau Rp 166,7 per kilogram. 
Tabel 2 Biaya, Keuntungan, dan Marjin Pemasaran Jamur Tiram Putih

\begin{tabular}{llr}
\hline No & \multicolumn{1}{c}{$\begin{array}{c}\text { Lembaga } \\
\text { Pemasaran }\end{array}$} & $\begin{array}{c}\text { Satuan } \\
(\mathbf{R p} / \mathbf{k g})\end{array}$ \\
\hline 1 & Petani & \\
& Harga Jual & $10.000,00$ \\
2 & Pedagang Pengecer & \\
& Harga Beli & $10.000,00$ \\
& Harga Jual & $14.000,00$ \\
& Biaya & $1.366,70$ \\
& Keuntungan & $2.633,30$ \\
& Margin & $4.000,00$ \\
\hline
\end{tabular}

Tabel 2 menunjukkan, , bahwa pelaku pemasaran yaitu pedagang pengecer di Desa Rajadesa ternyata memerlukan biaya $\mathrm{Rp} 1.366,70$ per kilogram dan keuntungan Rp. 2.633,30 dalam setiap satu kali proses pemasaran dan marjin pemasarannya Rp. 4.000 per kilogram.

Farmer's share adalah persentase harga yang diterima petani dari harga yang dibayarkan oleh konsumen. Untung ruginya petani tidak ditentukan oleh besar kecilnya nilai farmer,s share, tetapi dipengaruhi oleh harga produk dan biaya yang dikeluarkan.

Berdasarkan hasil penelitian menunjukkan bahwa harga jual jamur tiram ditingkat produsen Rp. 10.000,00 per kilogram, dan harga jual ditingkat pedagang pengecer Rp. 14.000,00 per kilogram, maka nilai Farmer's share nya adalah:

$$
\begin{aligned}
& \text { Farmer's Share }=\frac{\mathrm{Pf}}{\mathrm{Pr}} \times 100 \% \\
& \text { Farmer's Share }=\frac{10.000}{14.000} \times 100 \% \\
& \text { Farmer's Share }=71,5 \%
\end{aligned}
$$

Hasil perhitungan diketahui bahwa farmer's share sebesar 71,5 persen, hal ini menunjukkan bahwa bagian harga yang diterima petani adalah 71,5 persen dari harga yang dibayarkan oleh konsumen.

\section{KESIMPULAN DAN SARAN}

\section{Kesimpulan}

Berdasarkan hasil dan pembahasan, maka dapat diambil kesimpulan sebagai berikut :

1) Terdapat satu saluran pemasaran jamur tiram putih di Desa Rajadesa sampai ke tangan konsumen akhir yaitu :

Petan ->Pedagang pengecer ->Konsumen akhir.

2) Besarnya total marjin pemasaran adalah Rp. 4.000,00 per kilogram dengan total biaya pemasaran Rp. $1.366,70$ per kilogram dan total keuntungan pemasaran Rp. 2.633,30 per kilogram.

3) Besarnya bagian harga yang diterima Petani ( farmer's share ) adalah 71,5 persen. 


\section{Saran}

Berdasarkan kesimpulan diatas maka dapat disarankan hal - hal sebagai berikut:

1) Petani harus lebih kreatif untuk mencari trobosan baru yaitu dengan cara mengolah jamur tiram putih menjadi suatu produk kemasan siap saji yang dapat menghasilkan harga dengan nilai tinggi.

2) Petani dalam mengembangkan pasar harus lebih kreatif seperti memanfaatkan media cetak dan online.

\section{DAFTAR PUSTAKA}

Alex, S.M. 2011. Untung Besar Budidaya Aneka Jamur. Yogyakarta: Pustaka Baru Press.

Daniel. 2007. Kecerdasan Emosional. Jakarta: PT. Gramedia Pustaka Utama.

Nasehudin dan Gozali. 2012. Metode Penelitian Kuantitatif. CV. Pustaka Setia Bandung.

Andre, J.P. 2018 Analisis Pemasaran Jamur Tiram Putih. Pekbis jurnal, Faperta Agribisnis Universitas Riau.

Sugiyono. 2005. Metode Penelitian Administrasi. CV. Alfabet. Bandung. 